\title{
GRASSLAND NPP MONITORING BASED ON MULTI-SOURCE REMOTE SENSING DATA FUSION
}

\author{
YR. Cai ${ }^{1}$, JH. Zheng ${ }^{1,2,}$,,${ }^{*}$, MJ.DU $^{1}$, C.Mu ${ }^{4}$, J.Peng $^{4}$ \\ ${ }^{1}$ College of Resource and Environment Science, Xinjiang University, Shengli Road 666, Urumchi, China - yukipine@ 163.com \\ ${ }^{2}$ Key Laboratory of Oasis Ecology Ministry of Education, Shengli Road 666, Urumchi, China - zheng_jianghua@ 126.com \\ ${ }^{3}$ Institute of Arid Ecology and Environment Xinjiang University, Shengli Road 666, Urumchi, China -zheng_jianghua@126.com \\ ${ }^{4}$ Xinjiang Uygur Autonomous Region Grassland Station, Yan'er Wo Road 618, Urumchi, China -396862688@qq.com
}

KEY WORDS: Multi-source remote sensing; Data fusion; Net primary productivity; Carnegie-Ames-Stanford Approach model;

\begin{abstract}
:
Vegetation is an important part of the terrestrial ecosystem. It plays an important role in the energy and material exchange of the ground-atmosphere system and is a key part of the global carbon cycle process.Climate change has an important influence on the carbon cycle of terrestrial ecosystems. Net Primary Productivity (Net Primary Productivity)is an important parameter for evaluating global terrestrial ecosystems. For the Xinjiang region, the study of grassland NPP has gradually become a hot issue in the ecological environment.Increasing the estimation accuracy of NPP is of great significance to the development of the ecosystem in Xinjiang. Based on the third-generation GIMMS AVHRR NDVI global vegetation dataset and the MODIS NDVI (MOD13A3) collected each month by the United States Atmospheric and Oceanic Administration (NOAA),combining the advantages of different remotely sensed datasets, this paper obtained the maximum synthesis fusion for New normalized vegetation index (NDVI) time series in20062015.Analysis of Net Primary Productivity of Grassland Vegetation in Xinjiang Using Improved CASA Model The method described in this article proves the feasibility of applying data processing, and the accuracy of the NPP calculation using the fusion processed NDVI has been greatly improved. The results show that:(1) The NPP calculated from the new normalized vegetation index (NDVI) obtained from the fusion of GIMMS AVHRR NDVI and MODIS NDVI is significantly higher than the NPP calculated from these two raw data; (2) The grassland NPP in Xinjiang Interannual changes show an overall increase trend; interannual changes in NPP have a certain relationship with precipitation.
\end{abstract}

\section{INTRODUCTION}

As an important part of the global carbon cycle, terrestrial ecosystems are the major forces that absorb free carbon from the atmosphere and convert it into organic compounds (Vitousek, P.,M.,1997;Post, W.M.,1990). Grassland, as one of the most widely distributed ecosystems in terrestrial ecosystems, plays an important role in climate regulation and the global carbon cycle (Pu SL.,2004). Net primary productivity (NPP) refers to the total amount of organic matter accumulated by a plant in unit time and unit area. It is the total amount of organic matter produced by plant photosynthesis minus the respiration consumption. It also reflects the response of terrestrial ecosystems. And important parameters of global climate change (Chen LJ., 2002; Wo X., 2014; Chen Q., 2014; Zhang JC.,2015). NPP can be accurately obtained through field measurements, and model estimation is an effective method for regional or larger scale. Previous studies have proposed a large number of models (Cramer W.,1999), and along with remote sensing, satellite data development models have been widely used in the research of terrestrial NPP. The popularity of satellite data models is due to the fact that remote sensing images can provide continuous, dynamic, and comprehensive surface information for any region of the globe (Prince SD.,1995; Sellers P.,1995). Satellite coverage data and spectral vegetation index products (ie normalized difference vegetation index, NDVI) are the most commonly used core data for modeling large areas of NPP(Cramer W.,1999).
In the study of regional carbon cycle based on satellite data model, the quantity and quality of remote sensing data are the decisive factors for major and in-depth analysis. MODIS data sets with a spatial resolution of 250 meters to 1 kilometer have been applied to the spatio-temporal changes and potential factors of NPP in many research areas (Ciais P.,2014; Guo, Q.,2017). Although these studies have captured the spatial information of NPPs, they cannot analyze NPP changes and their relationship with environmental factors for a long time. Only data covers the data of the past decade, and no data were available before 2000 . The same limitations exist in the research of SPOT vegetation products (Zhang R.,2017). Research using Landsat data can provide more detailed spatial information, but due to the poor temporal resolution and cloud coverage, it is difficult to obtain continuous long-term sequences (Guan X.,2015). Since the 1980s, AVHRR datasets have been widely used for long-term regional NPP studies (Gitelson AA.,2012), but because of their spatial resolution of $8 \mathrm{~km}$, they have been commonly used in larger regions. In addition, in many papers it has been demonstrated that, due to the spatial heterogeneity of the data, coarse resolution can lead to significant loss of precision in the simulation of NPP. In general, further studies of the regional carbon cycle are limited by the mutual inhibitory properties of different sensors. Therefore, the key challenge in using remote sensing measurements in regional NPP research is to achieve long-term consistency and accuracy. Integrating remote sensing data from different sensors and synthesizing their respective advantages is the only way to solve the problem (Cheng Q.,2016).

\footnotetext{
${ }^{1}$ Corresponding author: Email:zheng_jianghua@126.com
} 


\section{STUDY AREA AND DATA}

\subsection{Overview of the study area}

The Xinjiang Uygur Autonomous Region, located between $34^{\circ}$ $22^{\prime} \sim 49^{\circ} 33^{\prime} \mathrm{N}$ and $73^{\circ} 32^{\prime} \sim 96^{\circ} 21^{\prime} \mathrm{E}$ in northwest China, was selected as the study area (Figure 1). The total area of the Xinjiang Uygur Autonomous Region is about 1.66 million square kilometers, and the mountainous landforms account for more than $90 \%$. Due to the special geographical location, topographic conditions and the effects of arid climate, Xinjiang's ecological environment is extremely fragile, with rare plant species, low coverage, and simple types and structures. Xinjiang grasslands are mainly distributed in Tianshan, Altai Mountains, and Kunlun Mountains.The Altun Mountains and Junggar Basin, the edge of the Tarim Basin and the banks of the rivers. The area of grassland is 15 times that of cultivated land and it is forest 22 times the forest area, accounting for $86 \%$ of the area's green vegetation. The vast plains and low mountains in Xinjiang show vast desert landscapes. The desert vegetation formed under the influence of geographical environment and bio-climate is the main body of Xinjiang and accounts for more than $42 \%$ of Xinjiang's land area.(Yang HF,2014)

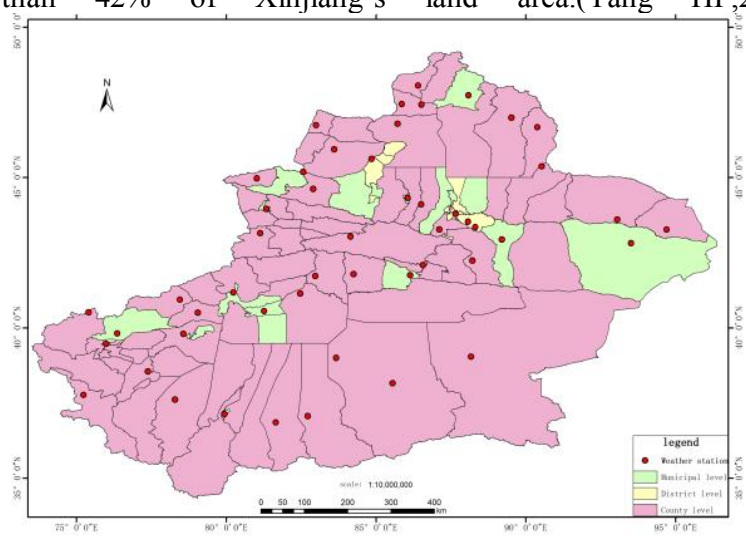

Figure 1.Location of the area

\subsection{Data and Processing}

The third generation (GIMMS3g) NDVI product of the global inventory modeling and cartographic research was selected as a basis to comprehensively use NOAA/AVHRR and MODIS monthly NDVI acquisition (MOD13A3) as a basis, and a 10year NDVI time series was combined at a scale of $1 \mathrm{~km}$. The GIMMS3g data set from 2006 to 2015 was obtained from the National Aeronautics and Space Administration (NASA). The data set has a spatial resolution of $8 \mathrm{~km}$ and a time interval of two weeks. Compared with other AVHRR-based NDVI products, this data set has better usability and quality (Beck HE,2011). The MOD13A3 acquisition data from 2006 to 2015 was obtained from the NASA Earth Observing System (EOS) project with a spatial resolution of $1 \mathrm{~km}$. These data are mainly used to study vegetation and land surface, and have been widely used in numerous vegetation studies (Pei F,2013). In this study, the monthly maximum GIMMS3g NDVI was obtained using a maximum synthesis (MVC) technique to match the MODIS data interval.

The vector data used include the Xinjiang Uygur Autonomous Region boundary map and the 1:100 million China Vegetation Atlas. Among them, the boundary map of the Xinjiang Uygur Autonomous Region is the Albers projection, a geodetic coordinate system, used to crop vector and raster data. The 1:100 Million China Atlas of Vegetation was digitized by the Chinese Academy of Sciences in 2007 and published in 2001 "Atlas of 1:1 Million Chinese Vegetation" digitized, then projected, matched, splice, and finally attributed, and was the medium-scale vegetation of the international scale. Illustration. This data is an Albers projection. This data can fully reflect the main vegetation types and their geographical distribution in China. This article is used by the National Natural Science Foundation of China's "Environmental and Ecological Science Data Center in Western China" (http://westdc.westgis.ac.cn).

The data used for spatial values of temperature and precipitation in this study is from the China Meteorological Data Network (http://data.cma.gov.cn/). The time series is from July 2006 to 2016, including 108 weather stations in Xinjiang. Temperature and precipitation data, as well as longitude, latitude, and elevation of each site. The data was checked for accuracy, discontinuity data, error data, and redundant data were discarded. Finally, 90 stations were used to perform spatial interpolation. Based on this, the average July precipitation and air temperature at each site were calculated.

\section{RESEARCH METHOD}

\subsection{Remote Sensing Data Fusion Method}

The application of NDVI time series data is usually caused by noise and errors caused by cloud and other atmospheric pollution. In order to obtain high quality NDVI time series, mobile weighted harmonic analysis (MWHA) method is used to correct the error values in MODIS NDVI and GIMMS3g data sets. After filtering, the displayed NDVI time series is closer to the actual vegetation change curve.

For the MDIS NDVI and GIMMS3g data, it can be seen that there is a large difference between NDVI between the two sensors, which may be due to the inconsistent characteristics of the two sensors and the lack of atmospheric correction of the GIMMS3g data (Steven MD.,2003; Gan W.,2014)Fensholt and Proud concluded that since the time trend of GIMMS NDVI acquisition is generally the same as that of MDIS NDVI data (Fensholt R.,2012), a one-dimensional linear regression normalization model can be used to express the relationship between two data sets.

Although the differences between the different sensors are reduced, there is a difference in the spatial resolution between the obtained MODIS NDVI and GIMMS NDVI time series. Since the spatial resolution of GIMMS $3 \mathrm{~g}$ data is too rough, it may lead to errors in the calculated NPP. Therefore, the method of multi-sensor fusion is an effective method to solve the spatial resolution of different data. In many vegetation studies, spatial and temporal adaptive reflectivity fusion models (STARFM) and extended STARFM (ESTARFM) have been applied to the integration and prediction of vegetation indices (Shen $\mathrm{H}$ et al ,2013; Schmidt M., 2012; Liu S., 2016) The STARFM model was used in this study to improve the spatial resolution of the data.

Based on the STARFM model, MODIS NDVI data of time series was constructed by merging MOD13A3 and GIMMS3g data. This model uses one or two pairs of MODIS, GIMMS3g data at $\mathrm{t} 0$ and MODIS data at $\mathrm{t} 1$, and combines different spatial weights to calculate the MODIS data at time t1. The formula is as follows: 
$\mathrm{L}\left(x_{w / 2}, y_{w / 2}, t_{1}\right)=\sum_{i=1}^{w} \sum_{j=1}^{w} \sum_{k=1}^{n} W_{i j k} \times\left(\begin{array}{c}M\left(x_{i}, y_{i}, t_{1}\right)+ \\ L\left(x_{i}, y_{i}, t_{0}\right)-M\left(x_{i}, y_{i}, t_{0}\right)\end{array}\right)$

Where $\mathrm{L}$ and $\mathrm{M}=$ the NDVI values of MODIS and GIMMS3g pixels

$\mathrm{W}=$ the weight function

$\left(\mathrm{x}_{\mathrm{i}}, \mathrm{y}_{\mathrm{i}}, \mathrm{t}_{0}\right)=$ a pixel at the position $\mathrm{t}_{0}\left(\mathrm{x}_{\mathrm{i}}, \mathrm{y}_{\mathrm{i}}\right)$

$\left(\mathrm{x}_{\mathrm{i}, \mathrm{yi}}, \mathrm{t}_{1}\right)=$ a pixel at position $\mathrm{t} 1\left(\mathrm{x}_{\mathrm{i}}, \mathrm{y}_{\mathrm{i}}\right)$

$\left(\mathrm{x}_{\mathrm{w} / 2}, \mathrm{y}_{\mathrm{w} / 2}, \mathrm{t}_{1}\right)=$ the center pixel of the moving window at time $t_{1}$.

\subsection{CASA Model}

CASA (Carnegie-Ames-Stanford-Approach) model is one of the most common models in the light energy utilization model. This research uses the improved CASA model of Zhu WQ et al. (Zh u WQ.,2005). The model study method is as follows:

$$
\operatorname{NPP}(\mathrm{x}, \mathrm{t})=\mathrm{A}_{\text {apar }}(\mathrm{x}, \mathrm{t}) \times \varepsilon(\mathrm{x}, \mathrm{t})
$$

Where $\operatorname{NPP}(x, t)=$ the net primary productivity of cell $x$ within t month

$\mathrm{A}_{\text {apar }}(\mathrm{x}, \mathrm{t})=$ the pixel $\mathrm{x}$ in month $\mathrm{t}$

$\varepsilon(\mathrm{x}, \mathrm{t})=$ the actual light energy utilization of pixel $\mathrm{x}$ in month $\mathrm{t}$

Based on Zhu WQ 's method, this paper uses MOD13A3 product data, fused data, and grassland type data to calculate the NDVIi,min, NDVIi,max and SRi,min, SRi,max。The maximum and minimum values of NDVI and SR for different vegetation types are shown in Table 1.

\begin{tabular}{ccccc}
\hline $\begin{array}{c}\text { Grassland } \\
\text { type }\end{array}$ & $\mathbf{N D V I}_{\mathbf{i}, \max }$ & $\mathbf{N D V I}_{\mathbf{i}, \min }$ & $\mathbf{S R}_{\mathbf{i}, \max }$ & $\mathbf{S R}_{\mathbf{i}, \mathbf{m i n}}$ \\
\hline $\begin{array}{c}\text { Meadow } \\
\text { Plain } \\
\text { grassland } \\
\text { Desert }\end{array}$ & 0.683 & 0.0356 & 5.3091 & 1.0487 \\
$\begin{array}{c}\text { grassland } \\
\text { Alpine and }\end{array}$ & 0.276 & 0.0356 & 1.7624 & 1.0487 \\
$\begin{array}{c}\text { Sub-alpine } \\
\text { meadow }\end{array}$ & 0.558 & 0.0356 & 3.5249 & 1.0487 \\
$\begin{array}{c}\text { Alpine and } \\
\text { Sub-alpine } \\
\text { plain }\end{array}$ & 0.130 & 0.0356 & 1.2396 & 1.0487 \\
grassland & & & & \\
\hline
\end{tabular}

Table 1. The maxmum and minmum values of NDVI and SR in different vegetation type

In the paper, according to Zhu WQ simulating the important algorithm of $\varepsilon_{\text {max }}$ of typical vegetation in China, different grassland species in Xinjiang region were added to simulate the $\varepsilon_{\max }$ of different grassland types in Xinjiang region. Different grasslands can be seen from Table 2 . The $\varepsilon_{\max }$ of the type is quite different, and the $\varepsilon_{\text {max }}$ of desert grassland and subalpine grassland is significantly lower than that of other grassland types, and is lower than the $\varepsilon_{\text {max }}$ maxsimulated by Zhu WQ .(Ren X.,2017).

\begin{tabular}{cc}
\hline Grassland type & $\varepsilon_{\max }$ \\
\hline Meadow & 0.575 \\
Plain grassland & 0.485 \\
Desert grassland & 0.131 \\
Alpine and Sub-alpine meadow & 0.568 \\
Alpine and Sub-alpine plain grassland & 0.087
\end{tabular}

Tble 2. Maxmum Utilization Rate of Vegetation Type of Main Grassland in Xinjiang Region

\section{RESEARCH RESULTS}

\subsection{Data Fusion Effect}

In order to verify the accuracy of the time series NDVI generated based on the STARFM model fusion MODIS data and GIMMS3g data, the 2015 NDVI data was merged using the MODIS NDVI data of July 2015 and GIMMS NDVI3g of the same time as the basis pairs. Comparison of real NDVI data during the period. Figure 2 shows the MODIS NDVI, GIMMS NDVI3g, and NDVI data based on STARFM model fusion over the same period. Compared with GIMMS NDVI3g data, the integrated NDVI data has significantly improved spatial resolution and more detailed spatial details. Compared with real MODIS NDVI data, spatial resolution and spatial information distribution trends are basically the same.

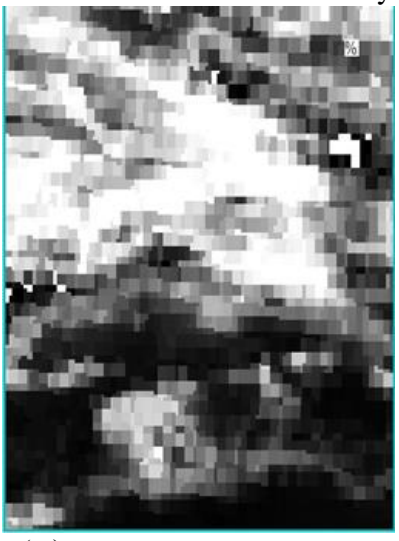

(a) 2015. 7GIMMS NDVI3g

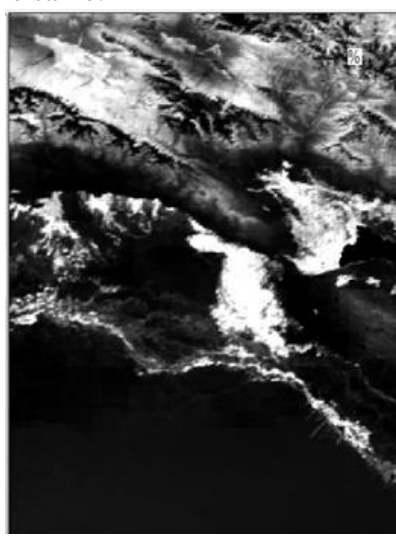

(b) 2015.7 MODIS NDVI

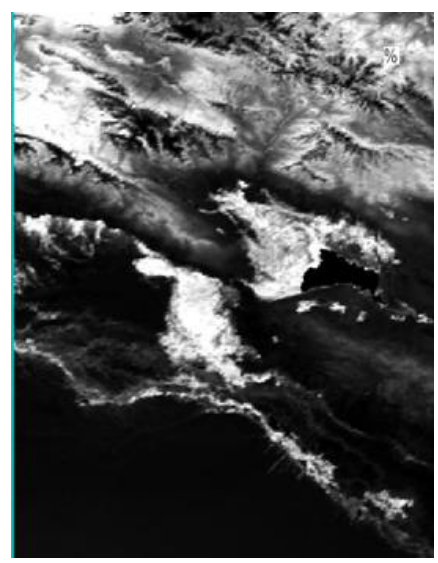

(c) 2015.7 Fusion NDVI

Figure 2.Comparison of GIMMS NDVI3g、MODIS NDVI and Fusion NDVI in local areas

\subsection{Validation of the CASA M Validation of the CASA model odel}

In order to verify the accuracy, applicability and reliability of ap plying the improved CASA model to Xinjiang grassland NPP es timation results, the necessary verification was carried out for th e estimated results. Usually, in the verification process, it is more common to compare the fitted data with the measured data, but there are few actual measured data in the Xinjiang region. There fore, this article uses the relevant literature to compare the study with other similar research areas or Research results of scholars of different estimation models. As can be seen from Table 3, the data in this study is significantly lower than that of other researc 
hers. This is because this study only simulated the grassland NP $\mathrm{P}$ in Xinjiang in July-Jul. 2006, while other scholars studied the a nnual grassland NPP. There is a big gap. The results of Yang HF (2014)research showed that the Xinjiang grassland NPP peaked i $\mathrm{n}$ July and the average NPP between July and July 2000 was bet ween 10 and $40 \mathrm{~g} \mathrm{C} /\left(\mathrm{m}^{2} \cdot \mathrm{a}\right)$. Ren X (2017) studies showed that th e NPP between 2000 and July 2012 The mean NPP is $50.93 \mathrm{~g} \mathrm{C} /$ $\left(\mathrm{m}^{2} \cdot \mathrm{a}\right)$, which is similar to the present study. However, different scholars use different remote sensing models to calculate the res ults are different, this may be due to the use of models, remote s ensing data, research scales and other differences caused by.

\begin{tabular}{|c|c|c|c|c|c|}
\hline Model & Area & $\begin{array}{l}\text { Remote } \\
\text { data }\end{array}$ & Year & $\begin{array}{l}\text { Grass- } \\
\text { land } \\
\text { NPP }\end{array}$ & $\begin{array}{l}\text { Refer- } \\
\text { ence }\end{array}$ \\
\hline OLECM & Xinjiang & $\begin{array}{l}\text { NOAA/ } \\
\text { AVHRR }\end{array}$ & $\begin{array}{l}1981- \\
2000\end{array}$ & 215.21 & $\begin{array}{l}\text { Liu } \\
\text { WG., } \\
2007\end{array}$ \\
\hline $\begin{array}{l}\text { BIOME } \\
\text {-BGC }\end{array}$ & Xinjiang & MOD17A3 & $\begin{array}{l}2000- \\
2010\end{array}$ & 145.6 & $\begin{array}{l}\text { Gao Y., } \\
2015\end{array}$ \\
\hline CASA & Xinjiang & MOD13A1 & $\begin{array}{l}2000- \\
2010\end{array}$ & 105.77 & $\begin{array}{l}\text { Yang } \\
\text { HF., } \\
2014\end{array}$ \\
\hline CASA & Xinjiang & MOD13A3 & $\begin{array}{l}2001- \\
2013\end{array}$ & 243.7 & $\begin{array}{l}\text { Wu } \\
\text { XQ., } \\
2016\end{array}$ \\
\hline CASA & Xinjiang & MOD13A1 & $\begin{array}{l}2000- \\
2014 / \\
\text { July }\end{array}$ & 50.93 & $\begin{array}{l}\text { Ren X., } \\
2017\end{array}$ \\
\hline CASA & Xinjiang & $\begin{array}{l}\text { MOD13A3 } \\
\& \text { GIMMS3g }\end{array}$ & $\begin{array}{l}2006- \\
2015 / \\
\text { July }\end{array}$ & 32.92 & $\begin{array}{l}\text { this } \\
\text { research }\end{array}$ \\
\hline
\end{tabular}

Table 3. Comparison of simulated NPP in the study and that by other different models

unit: $\mathrm{g} \mathrm{C} /(\mathrm{m} 2 \cdot \mathrm{a})$

Based on the analysis of the above results, there are some errors in the simulation, but within the allowable range of error variatio $\mathrm{n}$, we believe that the results of the improved CASA model simu lation can more reliably reflect the overall status of grassland NP $\mathrm{P}$ in Xinjiang, which has a certain degree of influence on Xinjian g grassland NPP. The value and estimation result also have high accuracy, so this model can be used to estimate grassland NPP i n Xinjiang.

\subsection{NPP spatial distribution and change trend}

Univariate linear regression was used to analyze the NPP time series evolution trend of grassland pixel by field in July 2006 to July 2015, and the distribution of grassland NPP in Xinjiang was obtained.

From July 2006 to July 2015, the grassland NPP in Xinjiang showed a slow and fluctuating overall growth (Figure 3 ). The average NPP ranged from 27.129 to $37.256 \mathrm{~g} \mathrm{C} /\left(\mathrm{m}^{2} \cdot \mathrm{a}\right)$, and the average NPP over this 10 -year period was $32.925 \mathrm{~g} \mathrm{C} /\left(\mathrm{m}^{2} \cdot \mathrm{a}\right)$. In 2007,2011 , and 2015 , the monthly average of NPP was $35.786 \mathrm{~g}$ $\mathrm{C} /\left(\mathrm{m}^{2} \cdot \mathrm{a}\right), 34.406 \mathrm{~g} \mathrm{C} /\left(\mathrm{m}^{2} \cdot \mathrm{a}\right)$, and $37.256 \mathrm{~g} \mathrm{C} /\left(\mathrm{m}^{2} \cdot \mathrm{a}\right)$, respectively. The monthly average of NPP is $29.484 \mathrm{~g} \mathrm{C} /(\mathrm{m} 2 \cdot \mathrm{a})$. Combined with the precipitation data from July 2006 to July 2015 (Figure 4), it can be seen that the NPP of grassland NPP 2007 has also reached a peak in Xinjiang, and the precipitation in 2009 has significantly decreased compared with other years, and the corresponding grassland NPP also decreased in the same year.
To the minimum, it can be seen that there is a certain relationship between NPP and precipitation in Xinjiang grasslands.

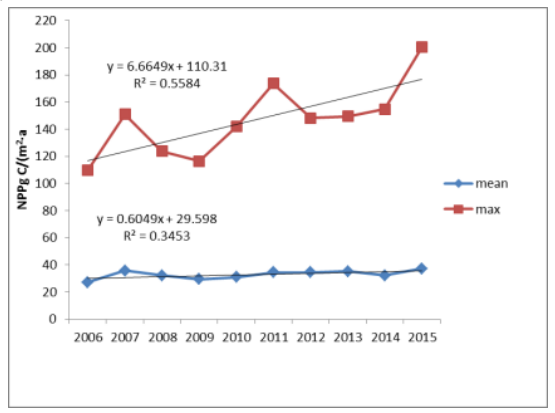

Figure 3. Variability of NPP values in XinJiang grassland from 2006to2015

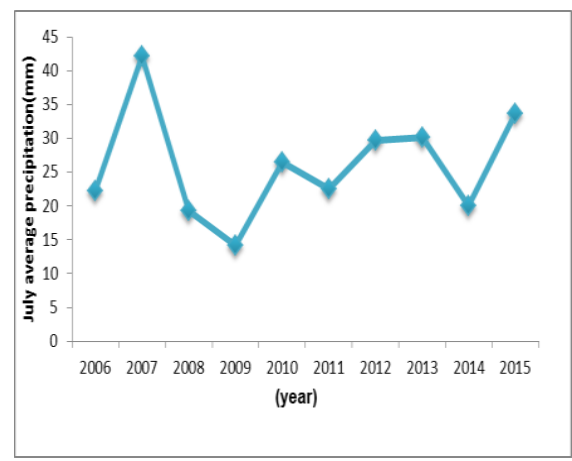

Figure 4.Average precipitation change in July 2006-2015

The average monthly NPP of grassland vegetation in Xinjiang during the period from July 2006 to July 2015 was $32.93 \mathrm{~g}$ $\mathrm{C} /(\mathrm{m} 2 \cdot \mathrm{a})$. Based on the MODIS NDVI data, the spatial distribution of grassland vegetation NPP in Xinjiang from July 2006 to July 2015 can be seen from Figure 5. Due to the influence of hydrothermal conditions, the spatial differences of NPP in grassland in different regions were obvious, showing the characteristics of high north and low in the south, high in the western region and low in the eastern region. This is due to the fact that the rainy waters in northern Xinjiang have more types of meadows and meadows than those in the southern part of China. In southern Xinjiang, there are few droughts in summer, and there are more deserts and grasslands in the desert. Therefore, the NPP in Xinjiang shows a clear northern Xinjiang has a higher distribution pattern than that of southern Xinjiang, with high west and low east.

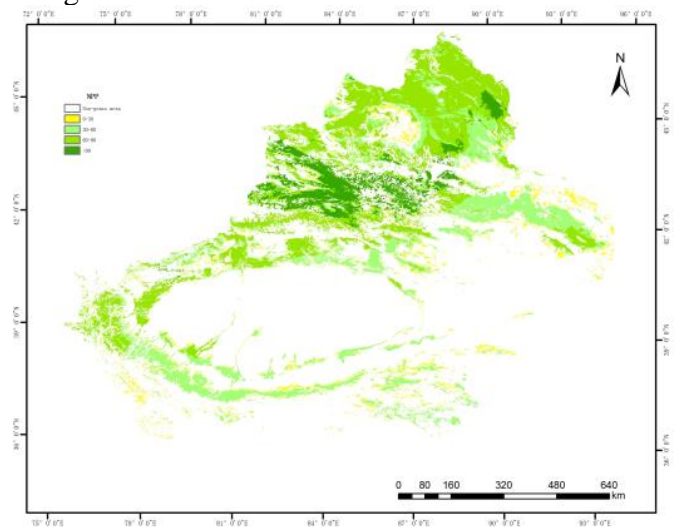

Figure 5.Spatial distribution of mean NPP in xinjiang grassland during 2006-2015 


\section{DISCUSSION}

\subsection{Effect of STARFM Model Parameter Adjustment on Results}

The parameters of the STARFM model have some influence on the quality of the fused image. The decision coefficient, root me an square error, average absolute difference, and standard deviat ion of the difference between the fused image and the reference 1 mage change with the adjustment of the parameter, but the rang e of change is limited. For a specific image, the number of classif ications determines the threshold value when similar pixels are s elected. The larger the number of classifications is, the more stri ngent the conditions for selecting similar pixels are, and the fewe $\mathrm{r}$ similar pixels exist in a particular window, the adjacent pixels $\mathrm{t}$ hat can be used. The less the information, the less able to fully e xpress the center pixel and reduce the accuracy of the result; but the small number of the classification will bring more misclassif ication phenomenon, that is, the non-identical pixels are determi ned as similar spectral pixels, which brings about error The infor mation is expressed on the center pixel to reduce the accuracy o $\mathrm{f}$ the result.

\subsection{Impact of Remote Sensing Image Accuracy on Results}

The accuracy of remote sensing images used in this study is not high enough. The MODIS product data set with $1000 \mathrm{~m}$ resolutio $\mathrm{n}$, GIMMS3g dataset with $8000 \mathrm{~m}$ resolution and grassland type map with $1000 \mathrm{~m}$ are used in this paper. The temporal resolution and spatial resolution can be selected in future research. All the data are relatively high, and the geomorphological factors and re mote sensing images should be taken into account to study the a lgorithms that can be used to interpret the vertical grassland spec ies in the arid region of Xinjiang, so as to improve the classificati on accuracy of the grassland species in the study area and to esti mate the grassland NPP in the study area. The model provides $\mathrm{m}$ ore reliable basic data, which will be used to correct the relevant parameters for grassland NPP estimation in the research area.

\section{CONCLUSION}

This paper is based on remote sensing spatio-temporal fusion technology and CASA model to estimate the high spatial resolution NPP method, and researches the grassland net primary productivity in Xinjiang Uygur Autonomous Region from 2006 to 2015. It combines the advantages of GIMMS3g data and MODIS data to obtain innovative results. Fusion NDVI time series. The comprehensive evaluation shows that the estimated NPP after NDVI fusion is not consistent with the MODIS NDVI estimation, and can effectively improve the accuracy of NPP compared with GIMMS NDVI3g data. Experimental results show:

(1) The time series NDVI obtained by the fusion model has a good effect and can be used in future NPP simulation and calculation;

(2) Based on the merged time series NDVI and NMP based on GIMMS3g data, it has finer spatial information;

(3) The improved CASA model can more reliably reflect the overall status of grassland NPP in Xinjiang.

In addition, the validation data of NPP simulation estimation in this study is only through consulting the literature and comparing the differences between the previous scholars and my research. In the subsequent research, we will use a variety of methods to verify the reliability of NPP simulation values, such as field measurement data, etc. method.

\section{ACKNOWLEDGEMENTS}

Xinjiang uygur autonomous region youth science and technolog $y$ innovation talent training project(2016); The XinJiang natural grassland health evaluation system and evaluation model researc $\mathrm{h}$ based on the remote sensing and GIS technology 2015-2016(6 2207)

\section{REFERENCES}

Vitousek, P.M., Mooney, H.A., Lubchenco, J., Melillo, J.M., 200 8.Human domination of earth's ecosystems[J].Science, 277(532 5),pp.494-499,https://doi.org/10.1007/978-0-387-73412-5_1.

Post, W.M., Peng, T.-H., Emanuel, W.R., King, A.W., Dale, V. H., De Angelis, D.L.,1990.The global carbon cycle[M].American Scientist,78, pp.310-326.

Pu SL, Fang JY, He JS, Xiao Y., 2004.Grassland vegetation bio mass and its spatial distribution pattern in China[J]. Chinese Jou rnal of Plant Ecology, 28(4),pp.491-498,doi: 10.17521/cjpe.2004. 0067.

Chen LJ., Liu GH., Li HG., 2002. Estimating Net Primary Produ ctivity of Terrestrial Vegetation in China Using Remote Sensing [J].Journal of RemoteSensing,6(2), pp.129-136,doi: 10.3321/j.iss $\mathrm{n}: 1007-4619.2002 .02 .010$.

Wo X., Wu LC., Zhang JP., Zhang LB., Liu WL., 2014. Estimati on of net primary production in the Three-River headwater regio $\mathrm{n}$ using CASA model[J]. Journal of Arid Land Resources and E nvironment, 28(9),pp.45-50.

Chen Q., Chen YH., Wang MJ., Jiang WG., Hou P., Li Y., 2014. Change of vegetation net primary productivity in Yellow River watersheds from 2001 to 2010 and its climatic driving factors an alysis[J]. Chinese Journal of Applied Ecology, 25(10),pp.2811-2 818.

Zhang JC., Zhang L., Zheng Y., Tian XJ., Zhou Y., 2015. Simula tion of vegetation net primary productivity and evapotranspirati on based on LPJ model in Central Asia[J].Prata cultural Science, 32(11),pp.1721-1729, doi: 10.11829〉j.issn.1001-0629.2015-0103. Cramer, W., Kicklighter, D., Bondeau, A.,Iii, B.M., Churkina, G., Nemry, B., Ruimy, A., Schloss, A.,Intercomparison, T., Bondea u, A.,et al., 1999. Comparing global models of terrestrial net pri mary productivity(npp): Overview and key results[J]. Global Ch ange Biology,5,pp. 1-15.

Prince, SD., Goward, SN.,1995. Global primary production: A re mote sensing approach[J]. Journal of Biogeography, 22 (4/5),pp. 815-835, doi:10.2307/2845983.

Sellers, P., Meeson, B., Hall, F.,Asrar, G.,Murphy, R.,chiffer, R., Bretherton, F., Dickinson, R.; Ellingson, R., Field, C., 1995. Re mote sensing of the land surface for studies of global change : M odels-algorithms-experiments[J]. Remote Sens. Environ., 39 (1),pp.3-26,https://doi.org/10.1016/0034-4257(94)00061-Q.

Ciais, P.; Dolman, A.; Bombelli, A.; Duren, R.; Peregon, A.; Ra yner, P., Miller, C., Gobron, N., Kinderman, G., Marland, G., 20 14. Current systematic carbon-cycle observations and the need $f$ or implementing a policy-relevantcarbon observing system[J]. B iogeosciences, 10 (13), pp. 11447-11581, doi: 10.5194/bgd-10-11 447-2013.

Guo, Q.,Fu, B., Shi, P., Cudahy, T.,Zhang, J., Xu, H., 2017. Satel lite monitoring the spatial-temporal dynamicsof desertification $\mathrm{i}$ $\mathrm{n}$ response to climate change and human activities across the or dos plateau[J]. Remote Sensing, 9 (6),pp.525, doi:10.3390/rs906 0525 . 
Zhang, R., Zhou, Y., Luo, H., Wang, F., Wang, S., 2017. Estimat ion and analysis of spatiotemporal dynamics of thenet primary $p$ roductivity integrating efficiency model with process model in $\mathrm{k}$ arst area[J]. Remote Sensing, 9 (5),pp.477, doi: 10.3390/rs90504 77.

Guan, X., Shen, H., Gan, W., Zhang, L., 2015. Estimation and S patiotemporal Analysis of Winter NPP in Wuhan based on Land sat TM/ETM+ Images[J]. Remote Sensing Technology \& Applic ation, 30(5),pp.884-890, doi: 10.11873/j.issn.1004-0323.2015.5.0 884.

Gitelson, A.A., Peng, Y., Masek, J.G., Rundquist, D.C., Verma, S., Suyker, A., Baker, J.M., Hatfield, J.L. ,Meyers, T., 2012. Rem ote estimation of crop gross primary production with Landsat da $\mathrm{ta}[\mathrm{J}]$. Remote Sensing of Environment, 121 (138), pp.404-414, ht tps://doi.org/10.1016/j.rse.2012.02.017Get rights and content.

Cheng, Q., Liu, H., Shen, H., Wu, P., Zhang, L., 2016. A spatial and temporal non-local filter based data fusion[J]. IEEE Transac tions on Geoscience \& Remote Sensing, PP (99), pp.1-13,doi: 10. 1109/TGRS.2017.2692802

Yang HF., Gai CC., Mu SJ., Zhang CB., ZhouW., Li J L., 2014. Analysis of the spatio-temporal variation in net primary producti vity of grassland during the past 10 years in Xinjiang [J]. Acta Pr ataculturae Sinica, 23(03),pp. 39-50,doi: 10.11686/cyxb20140305

Beck, H.E., Mc Vicar, T.R., van Dijk, A.I., Schellekens, J., de Je u, R.A., Bruijnzeel, L.A.,2011. Global evaluation offour avhrr-N DVI data sets: Intercomparison and assessment against Landsat imagery[J]. Remote Sensing of Environment, 115 (10), pp.25472563, https://doi.org/10.1016/j.rse.2011.05.012.

Pei, F., Li, X., Liu, X., Wang, S., He, Z., 2013. Assessing the dif ferences in net primary productivity between pre-andpost-urban land development in China[J]. Agricultural \& Forest Meteorolog y, s 171-172 (3), pp.174-186, https://doi.org/10.1016/j.agrformet. 2012.12.003.

Steven, M.D., Malthus, T.J., Baret, F., Xu, H., Chopping, M.J., 2 003. Intercalibration of vegetation indices from different sensor $s$ ystem[J]. Remote Sensing of Environment, 88 (4),pp.412-422, h ttps://doi.org/10.1016/j.rse.2003.08.010.

Gan, W., Shen, H., Zhang, L., Gong, W.,2014. Normalization of medium-resolution NDVI by the use of coarser reference data: Method and evaluation[J]. International Journal of Remote Sens ing,35 (21), pp.7400-7429, doi: 10.1080/01431161.2014.968684.

Fensholt, R., Proud, S.R., 2012. Evaluation of earth observation based global long term vegetation trends-comparing GIMMS and MODIS global NDVI time series. Remote Sensing of Enviro nment[J]. 119 (3), pp.131-147,https://doi.org/10.1016/j.rse.2011. 12.015 .

Shen, H., Wu, P., Liu, Y., Ai, T., Wang, Y., Liu, XP., 2013.A sp atial and temporal reflectance fusion model considering sensor $\mathrm{O}$ bservation differences[J]. International Journal of Remote Sensi ng, 34 (12), pp.4367-4383, doi: https://doi.org/10.1080/0143116 1.2013.777488.

Schmidt, M.; Udelhoven, T.; Gill, T.; Röder., 2012. A. Long ter $\mathrm{m}$ data fusion for a dense time series analysis with MODIS and Landsat imagery in an australian savanna. J. Appl. Remote Sens. 6, 063512.

Liu, S., Zhao, W., Shen, H., Zhang, L., 2016. Regional-scale win ter wheat phenology monitoring using multisensory spatio-temp oral fusion in a south central China growing area[J]. Journal of Applied Remote Sensing,10 (4), pp.046029,doi: 10.1117/1.JRS.1 0.046029 .

Zhu WQ.,2005. Estimation of net primary productivity of Chine se terrestrial vegetation based on remote sensing and its relations hipwith global climate change[D]. Beijing Normal University.
Ren X., 2017. Study on Correlation between Net Primary Produ ctivity and Meteorological Factors in Xinjiang Grassland Based on Improved CASA Model[D]. Xinjiang University. 